\title{
GLOBALIZACIÓN Y POSMODERNIDAD: DESAFÍOS AL APRENDIZAJE
}

\author{
MSc.Paulette Barberousse(*)
}

¿Qué posición ética puede tomar el docente universitario en tiempos de la posmodemidad? Justo ahora es cuando menos se atienden los discursos a cadémicos y surten mayor efecto los mensajes de los publicistas, los comunicadores y los portadores de los llamados textos "light"?

En la "aldea planetaria", las fuerzas económicas más poderosas afectan, por igual, a un habitante de cualquier geografía o cultura. En la vertiginosa expansión de la globalización, la transmisión de la información juega un papel fundamental.

"Hacer academia" en la posmodernidad implica un reto mayúsculo, pues el conocimiento no puede ser fácilmente convertido en un bien de consumo y corre el peligro de perder su esencia al convertirse en un producto más del mercado. Parece ser que, en mediode un panorama desolador, solo elfortalecimiento del sujeto en sus propias experiencias, pensamientos, deseos y afectos puede llevarmos a una utopia, la de recrear y soñar una universidad para el mayor bienestar humano.
At a time when academic discourse is less listened to and the messages of publicists, journalists and writers of the so called 'light texts' cause a much greater impact on the people, a question arises: Which ethicalstand can a college professor take in posmodem times?

In the global village, the most powerful economic forces take a toll on people and cultures everywhere alike. In the rapid expansion of globalization, the transmission of information plays a critical role.

"To be an academic" in postmodem times implies a major challenge, for knowledge cannot be iransformed easily into consumers' goods, without running the risk of losing its essence when transformed into another market commodity.

It looks as if in the mid of a desolating panorama, only the strengthening of the person in his/her own experiences, thoughts, wishes and feelings can lead us towards a utopia, namely, to dream and recreate a university aimed humanity's well-being. Básica del CIDE, Cos Rica. Máster en Ciencias Filosoficasas e Históricas por la Universidad Babes-Bolyai, Cluj-Napoca, Rumanfa. Máster en Educación con énfasis en Educaciónde Adultos porla UCR. Su experiencia docente, investigativa y de producción se inscribe en el marco de las temáticas de fundamentación teórica (filosofia, epistemología, historia, sociología, psicopedagogía educati vas) así como en el campo de la didáctica y pedagogía universitaria. E-mail: palette 1959@yahoo.com 
Debo confesar que la autoría de este ensayo es sin duda colectiva y compartida, aunque de sus limitaciones, aciertos y desaciertos me responsabilizo. Nace, de alguna manera, de las reflexiones que mi práctica docente e investigativa universitaria me plantea diariamente cuando planifico mis lecciones, atiendo estudiantes de tesis o simplemente discuto con mis colegas. Es, en realidad, un diálogo conmigo misma que ahora comparto en estos tiempos de perplejidad e incertidumbre, cuando se estremecen convicciones y visiones de mundo, cuando se replantean formas de ser, de pensar y de fabular. Aclarar el mapa de los problemas no es resolverlos, ciertamente, pero nos deja más tranquilos para continuar. De hecho, siempre la redacción de un ensayo nos impele a sistematizar nuestras preocupaciones y dudas. Y éstas sobran. Es bueno admitir que tengo más interrogantes que respuestas certeras. Tal vez sea el signo de los tiempos. Subyace a mis planteamientos, fundamentalmente , una preocupación ética que cuestiona mi propio accionar y me replantea la problemática de qué saberes son necesarios para nuestra diaria labor.

Y cabe preguntarnos en el marco de las coordenadas de nuestra realidad nacional y de la temática que nos ocupa ¿cómo ubicar la práctica pedagógica universitaria contemporánea en un mundo "global y posmoderno"? ¿Qué valor otorgarle al "saber" y al "saber pedagógico" en la era de la información, de la "sociedad educativa" y de la pedagogía y realidad virtuales? ¿Cuáles son las demandas educativas de la "civilización cognitiva" y los desafíos que plantea la "mundialización" al aprendizaje humano? ¿Qué influencias ejercen sobre nuestro discurso los planteamientos de Dakar 2000, las manifestaciones antineoliberales de Niza y Seattle, el nuevo renacimiento del alfabetismo y arte digital, las luchas sociales de ATTAC, el amor en tiempos de Internet y el debate mass-mediático entre el Foro Éconómico Mundial de Davos y el Foro Social Mundial de Porto Alegre?

Estas constituyen las principales interrogantes que pretenderemos plantear desde nuestra intervención a sabiendas de que, desde nuestra "exclusion" (a pesar de Bourdieu) de Tercer Mundo, reivindicar la educación equivale a reivindicar que en este mundo todos tengamos alguna inserción. Tan sólo alguna.

La sociedad global nos ubica al borde de una drástica ruptura epistemológica comparable, creo tan sólo, al descubrimiento de que la tierra no constituía el centro del universo en tiempos de Copérnico, o que el hombre ya no es hijo de Dios, según Darwin o que el individuo es un laberinto "poblado de inconsciente", según Freud.

Admitir que la historia de la globalización o mundialización comenzó en 1989 constituiría un acto arbitrario y cuestionable. También se la podría ubicar a partir del descubrimiento del Nuevo Mundo en 1492, que acompaña la expansión de la civilización occidental, o mejor dicho, del sistema capitalista mundial que 
exporta bienes económicos y culturales... Lo cierto es que la palabra "globalización" ha invadido nuestro discurso muy "fin de siglo". Los seguidores de Fernand Braudel se acordarán de la "economía- mundo" y los de Mc Luhan de la "ciudad planetaria". Sin embargo, su inserción en la vida cotidiana es muy reciente. La caída del muro de Berlín, la invención del World Wide Web por un tal Tim Berners-Lee y la liberación de los capitales en Europa son ya historia del siglo pasado. La noción de "globalización" forma parte hoy en día del sentido común. Al respecto, el sociólogo francés Pascal Riché nos plantea:

En 1989 el mundo sale de un gran espasmo que ha durado diez años: colapso del sistema tripolar Estados Unidos- Japón- Europa instalado después de la Segunda Guerra Mundial; ebullición en las países del Este estimulada por el movimiento polaco Solidaridad (1980) y luego por la perestroika rusa (1985); aumento de las preocupaciones ambientales; revolución neoliberal en Estados Unidos bajo la presidencia de Reagan, ... la instauración de un modelo económico fundado en la mayor libertad de mercado.

La interdependencia de los mercados provocada por las firmas "globales", en realidad conformadas por estrategias que coordinan y relacionan entre sí una multiplicidad de mercados y proveedores dispersos en el mundo entero, hace del planeta un gran "mercado" de producción e intercambio que elimina la autonomía de la política económica de los estados e impone sus puntos de vista y reglas de juego. Tal como lo confirma el investigador mexicano Sánchez-Ruíz:

Este siglo, entonces, ha presenciado la aceleración del tiempo histórico, en términos de la internacionalización-trasnacionalizaciónglobalización de economías, políticas y culturas, en especial ante el surgimiento y desarrollo de las grandes corporaciones transnacionales, que no conocen más fronteras que las de la rentabilidad a escala global, y mediante la emergencia de la tercera revolución tecnológicoindustrial.....Todo este largo proceso histórico ha traído cambios en la división internacional del trabajo. Ha consistido en la paulatina articulación e interdependencia (desigual) de los estados nacionales al moderno sistema capitalista mundial".

En junio del año 1995 se lleva a cabo en Budapest, auspiciado por la Sociedad Europea de Cultura, el Coloquio Internacional Los hombres de cultura 
ante las fuerzas de disgregación y de globalización en la sociedad actual. Henri Bartoli, presidente del Centro Francés de la Sociedad Europea de Cultura, en su ponencia "Mundialización y desorden" publicada por Cuadernos de Marcha nos comenta:

37.000 sociedades transnacionales con sus 170.000 filiales dominan la economía mundial, 172 sobre 200 pertenecen a Estados Unidos, Japón, Francia, Alemania, Reino Unido. Entre las 50 más grandes, 20 tienen su sede en Estados Unidos, 8 en Japon.

En 1992 el volumen acumulado de las transacciones comerciales de las 4 empresas transnacionales industriales más importantes del mundo (General Motors, RoyaL Dutch Shell, Ford, Exxon) equivalía al producto interno bruto de China, sobrepasaba al de Rusia y al del conjunto del continente africano... Los estados pierden el control de la economía de su propio territorio. Deben arreglarse con las grandes firmas, que no vacilan en entrar en conflicto con ellos desde el momento que obstaculizan su poder mundial. Oligarquías a las que ningún pueblo, ningún poder político ha confiado la responsabilidad de la economía mundial, se atribuyen el destino y ejercen un poder sin precedentes, asimilable en ciertas circunstancias a un auténtico derecho de veto.

Surge, entonces, la globalización como consecuencia de la internalización cada vez más acentuada de los procesos económicos, los conflictos sociales y los fenómenos político-culturales a escala mundial $y$, desde nuestra perspectiva, constituye la configuración de la economía-mundo "global". Coincidimos con Scarlato cuando afirma:

Este proceso, en principio económico está acompañado de nuevas configuraciones políticas del mapa mundial, redefiniendo los papeles de los actores nacionales (estados, gobiernos, empresas clases y movimientos sociales) y extranacionales (viejos y nuevos organismos internacionales, empresas transnacionales, organizaciones no gubernamentales, etc.) en el escenario mundial. Los mayores y más acelerados (aunque también desiguales) contactos entre las múltiples culturas que pueblan el planeta constituyen orro rasgo fundamental del "nuevo mapa del mundo". 
En este sentido, García Canclini comenta que :

...pese a la diversidad e intensidad de los procesos de globalización, ésta no implica la unificación indeferenciada ni la puesta en relación simultánea de todas las sociedades entre sí. Los países acceden de manera desigual y conflictiva a los mercados económicos y simbólicos internacionales..." (destacado nuestro)

Es decir, el proceso expansivo del sistema capitalista mundial y de la "civilización occidental" nunca ha podido prescindir de hegemonías y desigualdades mundiales y regionales. Sin duda alguna, el aumento vertiginoso de las disparidades que agudizan los procesos de heterogenización social, la concentración de la riqueza y el estancamiento económico, el desempleo y sobrecalificación, la pobreza, marginalidad y exclusión de las grandes mayorías constituyen sus principales logros. Los seres humanos nos sumimos en la perplejidad, nos tornamos incapaces de conocernos y transformarnos, se diluye el individuo como sujeto de la razón y la historia .

Como nos recuerda el filosófo brasileño Octavio Ianni:

...son múltiples, nuevas y recreadas las formas del espacio y el tiempo develadas por los desdoblamientos de la globalización: el local y el global, el micro y el macro, la homogeneidad y la diversidad, la primacía del presente y la recreación del pasado, la contemporaneidad y la no-contemporaneidad, el norte y el sur, el Occidente y el Oriente, lo real y lo virtual, la experiencia y el simulacro, la desterritorialización y la miniaturización, el mensaje y el video-clip, la velocidad y el instante, lo fugaz y el silencio... Se intercambia la experiencia por la apariencia, lo real por lo virtual, el hecho por el simulacro, la historia por el instante, el territorio por el dígito, la palabra en la imagen... Entre utopías y nostalgias tejemos el mundo...".

El sistema educativo de nuestros países latinoamericanos y, en particular, el sistema universitarioestatal nacional, no sólo no se escapa de estas coordenadas socio-económicas, políticas y culturales de la realidad contemporánea, sino que crece y se desarrolla y se reproduce en su seno.

Y si a esta panorámica "globalizante" le añadimos la existencia de una cultura "posmoderna" que tiende a lo fragmentado, inmediato, efímero y frívolo, cuyos rasgos en la vida cotidiana son puntualizados por Gilles Lipovetski en su obra La Era del vacio: 
... época del narcisismo "cool" en que todas las relaciones son tibias y descomprometidas, se impone el goce del instante evitando lo displacentero y el dolor, por ello, se establecen relaciones interpersonales breves y sin vinculación afectiva profunda. Es visible el intento de vivir permanentemente como jóvenes, con cuidado al detalle del propio cuerpo, asistencia a los grupos "psi", abandono de los roles tradicionales asignados a los adultos. Se asiste a la desaparición de los compromisos ideológicos y aún axiológicos que exijan coherencia o planteen rigidez: se trata de librarse de demandas políticas y éticas para poder instalarse en un nuevo individualismo donde lo fundamental es disfrutar de cuanto está al alcance".

Otros autores como Baudrillard y Lyotard ponen de manifiesto otras características concomitantes como el abandono de los "grandes relatos ideológicos" y de la filosofía de la historia; proliferación de múltiples juegos lingüísticos diferenciados con el avance de las especializaciones tecnológicas y la creciente complejidad social; legitimación de la ciencia por su valor pragmático y no epistémico, abandono de la verdad por la adhesión a la eficacia, aceptación de la tecnocratización creciente sostenıda, sin embargo, junto al rechazo de la noción típica de "progreso". Y como bien lo señala Roberto Follari:

...hay un predominio del mundo visual: una generalización del universo de la imagen, una modificación de los parámetros perceptuales de referencia por la ubicación como permanentes sujetos visuales, si es posible con mecanismos de control a la mano que permitan la manipulación y selección de aquello a mirar. Todo esto creemos que resulta familiar a la experiencia colectiva contemporánea. La pérdida de interés por la lectura, el escaso apego a reglas universales de conducta, la porosidad y borramiento de las identidades, la estática presencia ante el televisor, forman parte de lo que diariamente enfrentamos".

Consolidado hacia mediados del siglo XIX, el proyecto histórico modemista se afianza en una serie de creencias fundacionales, tales como que la ciencia constituye la única fuente del conocimiento, postulando al racionalismo cientificista; la creencia en el individuo como un ego aislado y consumista que propone un individualismo mercantilista y moralmente anárquico y la creencia en la historia entendida como un proceso natural regido por leyes deterministas que promulga el llamado historicismo naturalista. 
El sentido radical de ruptura de fin de siglo estaría determinado, entre otros factores, por la desaparición del socialismo real en Europa; la valoración social positiva del mecanismo económico de mercado; el advenimiento de la economía planetaria; el surgimiento de una red cibernética global; el fin de la bipolaridad del mundo de posguerra; la crítica al racionalismo cientificista y al relativismo moral tendencialmente anárquico así como el reconocimiento recíproco de valores y experiencias entre distintas regiones geográficas y culturales.

Capítulo aparte merecen las facilidades tecnológicas pero también las dificultades de comunicación que provoca el impacto de Internet, en general, en la sociedad actual, en los procesos educativos, culturales, de identidad y de interculturalidad que constituyen la temática de base para el Forum Universal de las Culturas, por celebrarse en Barcelona en el 2004. Es válido señalar, no obstante, las desigualdades de los niveles de acceso a Internet en los contenidos y en la producción de información que cobra ribetes dramáticos al comparar porcentajes y países, datos que no hacen más que reflejar las desigualdades tecnológicas y económicas a escala planetaria.

Todas las sociedades, a lo largo de la historia, han sido sociedades de la información, pero podemos aseverar que nunca los cambios en este sector han sido tan acelerados como en las últimas décadas. Sin duda, los espacios de comunicación se amplían y, de alguna manera, se desterritorializan. Sin embargo estamos, al mismo tiempo, frente a una gran opulencia y a una gran miseria de información: datos recientes de la OCDE (2000) indican que en 1999 Canadá y Estados Unidos daban cuenta del $56 \%$ de los usuarios de Internet en el mundo, Europa casi una cuarta parte, es decir, 24\%, el área Asia-Pacífico 17\%, Medio Oriente $0.4 \%$, África $0.9 \%$, mientras que América Latina tan solo el $2.6 \%$.

A su vez, la decadencia del paradigma modernista ha propiciado el relanzamiento y enriquecimiento de paradigmas teóricos cuyas raíces se encuentran en el pasado, tales como el paradigma democrático y liberal que enfatiza la importancia del diálogo intersubjetivo, de la participación ciudadana y de la descentralización, desburocratización y autogestión de los procesos sociales; el paradigma del realismo o meta-realismo epistemológico enriquecido por los avances de las ciencias físico-matemáticas y naturales; el paradigma de la metafísica del ser, que subraya la dependencia existencial del ser humano con respecto a un ser supremo y fundamenta el primado de la persona frente a las estructuras sociales y por último, el paradigma que concibe la historia como una creación de la libertad.

De esta manera, la modernidad "positiva" que propone como principal estandarte el dominio racional y técnico sobre la naturaleza y la eliminación del "otro", de lo "diverso", de lo "heterogéneo", cede el paso, a trompicones y no 
Esta degradación de la calidad respecto a la cantidad es sintoma de nuestra crisis de civilización, pues vivimos en un mundo dominado por una lógica técnica, económica y científica. Sólo es real aquello que es cuantificable. La desorientación resulta, pues, evidente sin codazos, a una "posmodernidad" que sienta en el banquillo de los acusados a la razón, a la lógica tradicional y sus certezas absolutas. Postula como divisa la instauración de un nuevo paradigma emergente holístico e integral, complejo, ecológico, dinámico y flexible que intenta romper con las dualidades sujeto/ objeto, valor/hecho, mente/cuerpo,

intuición/razón, espíritu/materia, sentimiento/pensamiento, sintesis/análisis y que esgrime la unidad en la diversidad, el pensamiento complejo y divergente y la interdependencia en las más variadas esferas de la actividad humana .

A fin de superar la crisis multiforme y las disfunciones sociales que atravesamos, Edgar Morin, precursor de la teoría del pensamiento complejo, nos propone y nos obliga a reflexionar cuando expresa, comentando en una entrevista su última obra, Une politique de civilisation:

Todo aquello que constituyó la faz luminosa de la civilización occidental presenta ahora un envés cada vez más negro. Así, el individualismo, que es una de las grandes conquistas de la civilización occidental, genera hoy cada vez más fenómenos de atomización, de soledad, de egocentrismo o de degradación de la solidaridad. Otro producto ambivalente de nuestra civilización es la técnica, que ha descargado a los hombres de enormes gastos energéticos confiándoselos a las máquinas, pero ha hecho que la sociedad sea esclava de la lógica cuantitativa de dichas máquinas... La industria, que produce masivamente bienes baratos para satisfacer las necesidades de gran número de personas, es la causa de la contaminación y de la degradación que amenazan a nuestra biosfera. En este sentido, el automóvil es un perfecto ejemplo de los vicios y virtudes de nuestra civilización. Incluso la ciencia, de la que se pensaba que sólo aportaba beneficios, conlleva aspectos preocupantes como son el peligro atómico o la manipulación genética. Así pues, podemos decir que el mito del progreso, fundamento de nuestra civilización que pretendía que el mañana sería indudablemente mejor que el presente, y que compartiar: el mundo del oeste y el mundo del este ha caído en cuanto al mito. Lo que no significa que el progreso sea imposible, sino que no puede considerarse 
como algo automático y que suscita también regresiones de todo tipo. Actualmente hemos de reconocer que la civilización industrial, técnica y científica crea tantos problemas como los que resuelve.

Reafirma que el desarrollo, contemplado únicamente desde un punto de vista económico, no descarta ni mucho menos un subdesarrollo humano y moral y que ignoramos aún si la elevación del nivel de vida que promete la economía llamada "mundializada", no va a generar una degradación de la propia calidad de vida.

Esta degradación de la calidad respecto a la cantidad es síntoma de nuestra crisis de civilización, pues vivimos en un mundo dominado por una lógica técnica, económica y científica. Sólo es real aquello que es cuantificable. La desorientación resulta, pues, evidente.

Sin embargo, propone que si bien la mundialización tiene evidentemente un aspecto muy destructor por propiciar el anonimato, la uniformidad de culturas, la homogenización de las identidades, representa también una oportunidad única para los seres humanos de las diferentes culturas del planeta de comunicarse, comprenderse y favorecer los mestizajes. La pregunta está planteada: la globalización ¿apocalíptica o integrable? Los bandos "globalizantes" y "antiglobalización" se dividen según se divinice o se satanice el proceso y dependiendo desde qué contexto se le mire y desde qué perspectiva (como galeotes o pilotos con brújula al decir de Alain Touraine). Propone Morin, en última instancia, la unidad de lo múltiple y la multiplicidad de lo uno como principio básico para entender la realidad en forma holística y ecológica ya que sus estructuras surgirían de las interrelaciones e interdependencias de sus partes. Este enunciado nos conduce directamente a la propuesta de la educación global. $Y$ agrega, alegando la necesidad de un nuevo Renacimiento opuesto a esta nueva Edad Media tecnológica que parecemos vivir:

El conocimiento sólo es pertinente cuando se es capaz de contextualizar su información, de globalizarla y situarla en un conjunto. Sin embargo, nuestro sistema de pensamiento que impregna la enseñanza de la escuela primaria a la universidad, es un sistema parcelario de la realidad y hace que las mentes sean incapaces de relacionar los distintos saberes clasificados en disciplinas. Esta hiperespecialización de los conocimientos, que conduce a extrapolar un solo aspecto de la realidad, puede tener importantes consecuencias humanas y prácticas en el caso, por ejemplo, de las políticas de infraestructuras que muchas veces ignoran el contexto social y humano. Contribuye igualmente a 
despojar a los ciudadanos de las decisinnes políticas a favor de los expertos.

La reforma del pensamiento enseña a afrontar la complejidad con ayuda de instrumentos, de conceptos capaces de relacionar los diferentes saberes que están a nuestra disposición en este fin del siglo XX.

Frente al pensamiento complejo, la globalización, como proceso irreversible e inmodificable (incluida la cultural), pretende imponer un único modelo de pensamiento posible que postula que el neoliberalismo es "la" alternativa posible de política pública nacional, regional y municipal.

Con respecto a esta temática, el sociólogo alemán Ulrich Beck nos comenta en su libro ¿Qué es la globalización? :

El desarrollo del mercado mundial tiene consecuencias importantísimas para las culturas, identidades y modos de vida. La globalización del quehacer económico está acompañada de un proceso de globalización cultural. También aquí se trata, primordialmente, de la fabricación de símbolos culturales, una realidad que se viene observando desde hace ya bastante tiempo. Una buena parte de la sociología y del público en general, han adoptado para este problema una postura que se acerca bastante a la tesis de la convergencia de la cultura global. Según dicha tesis, se está produciendo una paulatina universalización, en el sentido de unificación de modos de vida, símbolos culturales y modos de conductas transnacionales. Tanto en una aldea de la Baja Baviera como en Calcuta, Singapur o en las fabelas de Río de Janeiro se ven los mismos culebrones televisivos, se llevan los mismos vaqueros y se fuma el mismo Marlboro como símbolo de "una naturaleza libre e incontaminada". En una palabra, la industria de la cultura global significa cada vez más la convergencia de símbolos culturales y de formas de vida.

A pesar de esta fuerte tendencia homogenizante, el "mundo que respiramos" según Benedetti, sigue siendo un verdadero mosaico, múltiple y plural que lucha y se expresa a través de los nuevos movimientos sociales (minorías étnicas, culturales, sexuales, feministas, ecológicos, pacifistas, etc.) que vanguardizan una creciente oposición y que se han transformado, en la última década, en interlocutores lúcidos y protagónicos que propugnan la construcción de un mundo mejor para todos.

Para muestra valga un botón: el Foro Social Mundial de Porto Alegre (Brasil) cuya realización coincidió con la reunión, en el lujoso centro turístico 
de esquí de Davos (Suiza), del Forum Económico Mundial financiado por más de mil corporaciones multinacionales y que cumple un papel estratégico en la formulación del pensamiento de los defensores de las políticas neoliberales en todo el planeta. Más de 1000 organizaciones de 120 países piensan que ha llegado el momento de organizar y de dar coherencia a las acciones del vasto movimiento mundial surgido para contrarrestar la globalización neoliberal que comenzó en 1998 con las movilizaciones en Europa contra el Acuerdo Multilateral de Inversiones, irrumpió impetuosamente en Seattle a fines de 1999 y continuó el año pasado en Washington, Praga y Niza con multitudinarias protestas contra las políticas del Fondo Monetario Internacional (FMI) y el Banco Mundial (BM). Estas grandes manifestaciones pusieron en evidencia la insurgencia de un movimiento cívico que trasciende las fronteras nacionales y que repreșenta un paso cualitativamente nuevo para la construcción de un contra-poder planetario. Las naciones del Tercer Mundo, así como los pobres y excluidos de los países desarrollados, padecen los efectos de las políticas devastadoras de la globalización liberal y la dictadura de los mercados que conducen el FMI, el BM y la Organización Mundial del Comercio (OMC) y parecen revivir el espíritu de los viejos tiempos del Mayo Francés 68 que rezaba en un graffiti: "Arriesga tus pasos por caminos que nadie anduvo; arriesga tu cabeza pensando en lo que nadie penso".

En este Foro que intenta construir "una alternativa a la barbarie", como lo expresó el gobemador de Río Grande del Sur, se sintió con gran fuerza la presencia de la Asociación por una Tasa a las Transacciones financieras especulativas para Ayuda a los Ciudadanos (ATTAC) que cuenta hoy en día con crecientes filiales y simpatizantes a nivel mundial.

Se organizaron los intercambios, foros, talleres y encuentros en función de cuatro ejes temáticos básicos: producción de riquezas y reproducción social; afirmación de la sociedad civil y los espacios públicos; poder político y ética en la nueva sociedad y acceso a las riquezas y a la sustentabilidad. La lista de temas analizados fue variopinta: acuerdos regionales, en particular ALCA, impuesto Tobin, Plan Colombia, transgénicos, género, ambiente, desarrollo sustentable, democracia, identidad cultural, exclusión social, tortura, discriminación racial, juventud, derechos humanos, derechos económicos, sociales y culturales, responsabilidad empresarial social, voluntariado, drogas, salud pública, ciudades sustentables, deuda externa, cooperación internacional, vivienda, presupuesto participativo, movimientos sociales, educación y universidades.

Democratizar la cultura y los saberes y "un mundo donde quepan todos los mundos" (al decir de los zapatistas) constituyeron sus principales estandartes. 
Mientras Davos globaliza el capital, Porto Alegre expande lo nuevo, lo diverso, lo avasallante a través de alternativas, propuestas y recelos que cifran sus esperanzas en que, del siglo XXI, surja un proyecto de sociedad que rescate el sentido de humanidad en toda la acepción del término.

En medio de este torbellino neoliberal y sus contrapropuestas y a pesar de que ni el proyecto modernista ni la posmodernidad pueden concebirse como homogéneos (mucho menos en el escenario latinoamericano donde conviven y subsisten diferentes tipos de modernidades con rasgos de posmodernidad), podemos relevar una cierta tendencia, lógica de suponer en la cultura posmoderna, de que todo entra en crisis de legitimación, pertenencia y pertinencia: instituciones educativas, docentes, valores y saberes.

La ensayista argentina Beatriz Sarlo, con su Premio Casa de las Américas 2000 sobre Cultura, política, medios e Internet, nos plantea que la reorganización del mundo de las ideas a partir de la transferencia de funciones típicamente intelectuales y políticas a la industria comunicacional es el rasgo más notable de la vuelta de siglo. Afirma que en la producción social de opinión los intelectuales han perdido su lugar y están siendo sustituidos por comunicadores y publicistas. Asistiríamos al ocaso del discurso intelectual y, en consecuencia, al descrédito creciente del papel del docente y sus instituciones en la vida pública, es decir, universidades, sus saberes y docentes.

Nuestras instituciones nacieron bajo una fuerte influencia del modelo de la Universidad de Salamanca y desde mediados del siglo XIX del modelo francés napoleónico con su característica división en facultades y carreras profesionales.

Hasta 1810 y durante el período colonial fueron reductos conservadores. No es sino hasta finales del XIX que se reconstituyen las viejas instituciones, que, al decir de Sarmiento, eran "tan atrasadas, tan escolásticas, tan rutineras como las españolas, a las que no le iban en zaga" (según Beck, 1998). Durante este siglo se consolida su sesgo profesionalista pero siempre alejado de la vida productiva y sus demandas. 1918 se recordará como el año de la Reforma de la Universidad de Córdoba que busca afirmar la libertad de pensamiento, la renovación de las cátedras, la participación estudiantil y la autonomía y cuyo legado se regará como pólvora por toda la América Latina. Se genera el rechazo a concebir a la universidad pública como "torre de marfil" y se la comienza a visualizar como la conciencia lúcida y crítica de la sociedad, como espacio de socialización y democratización de los conocimientos y saberes que promovería una mayor participación ciudadana, enarbolando las promesas de igualdad y justicia social. Se concibe a la educación como un derecho cívico, político y social. De hecho, mi generación se convierte en la fiel aliada de la instrucción pública, laica y obligatoria de la que nos sentimos herederos. Sin embargo, hoy 
En la producción social de opinión los intelectuales han perdido su lugar y están siendo sustituidos por comunicadores y publicistas. Asistiríamos al ocaso del discurso intelectual y, en consecuencia, al descrédito creciente del papel del docente y sus instituciones en la vida pública, es decir, universidades, sus saberes y docentes en día, se somete a las universidades a verdaderas torturas de autoevaluación y análisis de gestión de "calidad" para que, mediante rigurosos actos de constricción confiesen sus culpas y pecados frente al gran diosmercado. La creación original de nuevos conocimientos y la búsqueda de la verdad no se pueden vender ni resultan rentables; los esfuerzos para su

construcción se devalúan frente al éxito material fácil e inescrupuloso. El conocimiento se torna una mercancía más, sujeta a las leyes del mercado salvaje.

Gimeno Sacristán connota en Poderes inestables de la educación, subrayando la idea de que son los motivos personales y sociales los que dan sentido a la educación:

En esta época nos toca pensar y decidir el curso por el que queremos que transcurra la realidad social y la de la educación dentro de coordenadas inseguras... pensamos que la tarea de educar debe ser dirigida por algunas ideas-fuerza plasmadas en proyectos compartidos y asumidos individualmente... La crisis de los sistemas educativos tiene que ver con la pérdida de la conciencia sobre su sentido... conviene rescatar la idea de que, precisamente en las sociedades donde los elementos simbólicos y culturales desempeñan papeles tan importantes, el discurso puede tener algún valor de propuesta y de cambio (destacado nuestro).

Durante la década Jomtiem-Dakar, es decir de 1990 a la fecha, se han producido cambios significativos en el mundo cuyas consecuencias incidieron en el cumplimiento de los propósitos que se planteó la Educación para Todos: caídas de regímenes políticos, guerras civiles, fluctuaciones económicas y progresos científico-tecnológicos que afectaron de manera diferente regiones y países. Las orientaciones programáticas tendieron, sustancialmente, hacia una amplificación de la acción a escala mundial en pro del mejoramiento cualitativo de la educación; el desarrollo de los conocimientos de base y las capacidades de análisis y, además, la identificación y clarificación de áreas y dominios que reclaman una acción concertada. La educación como derecho humano universal, el aprendizaje permanente y de calidad y la erradicación del analfabetismo (se calculan 900 millones de los cuales más del 60\% son mujeres) estuvieron en el centro de estas discusiones. También se cuestionaron los cambios de las políticas 
educativas en los diversos y variados contextos sociales y culturales, dependiendo de las situaciones económico-financieras y en las modalidades de vida cotidiana de las comunidades, teniendo en cuenta a niños, jóvenes y adultos.

Desde la perspectiva latinoamericana el respeto a la vida humana digna, la construcción de una cultura de paz, el respeto a la diversidad étnica y cultural y su patrimonio así como el desarrollo sustentable y sostenible, fueron temas obligados de su agenda. Acceso, equidad, calidad, pertinencia y eficacia constituyeron los problemas y necesidades comunes en los planteamientos del Tercer Mundo.

Dakar 2000 proyecta sus iniciativas hacia el 2015 intentando profundizar los logros de Jomtiem y enfatiza la necesidad de alcanzar un aprendizaje de calidad para todos. "Aprender a aprender", uno de los pilares del Informe Delors para la educación del siglo XXI, se erige como una meta social deseable y un factor indispensable en el progreso personal y social tranformándose en una demanda educativa de la sociedad cognitiva. Generadas por las implicaciones sociales de las revoluciones tecnológicas en la producción, organización y difusión del conocimiento, las estrategias metacognitivas se han transformado en una necesidad formativa básica en la sociedad contemporánea. La nueva "cultura del aprendizaje", entendida como formas de aprender y enseñar y como condicionante de los fines de la educación, se caracteriza por tres rasgos esenciales:

1. presencia de una sociedad de la información no pocas veces fragmentada y distorsionada que necesita de nuestra capacidad para organizarla e interpretarla críticamente;

2. existencia de una sociedad del conocimiento múltiple y relativizado caracterizada por una gran diversidad informativa y la obligación, en función de la movilidad profesional y la aparición de nuevos perfiles profesionales y laborales para favorecer una...

3. formación profesional permanente.

Ante esta realidad, la "educación global" en el mundo hispano se caracteriza, según Ramón Flecha, por la tendencia a propiciar el "aprendizaje dialógico" que se basaría en los principios de :

diálogo igualitario, inteligencia cultural, la transformación, la dimensión instrumental, la creación de sentido, la solidaridad y la igualdad de diferencias. 
Otros autores, como Fernando Imbernón, plantean la diversidad como centro del proyecto educativo y consideran al entorno social como principal condicionante del aprendizaje: su gestión colectiva, la utilización de medios tecnológicos así como el respeto y la atención a necesidades y culturas específicas de los individuos.

En su reciente visita, la curriculista chilena Victoria Peralta nos señalaba:

A partir del mensaje crítico y liberador de Paulo Freire, muchas propuestas más recientes de "educación popular", "educación para la democracia", "educación para la diversidad", "educación para la modernidad", "pedagogía crítica" entre otras, han tratado de abordar la dialéctica de lo "global y lo local", a lo que habría de agregar también las propuestas actuales de educación intercultural bilingüe... el choque de las culturas de pertenencia con las culturas dominantes...se ha ido reemplazando en las últimas décadas por la "cultura global.

La globalización no sólo representa un gran desafío de carácter político y económico sino, sobre todo, un desafío para el pensamiento humano y para el aprendizaje. La explosión del consumo de recursos naturales, el desmedido crecimiento demográfico, la destrucción del medio ambiente, los desequilibrios financieros y económicos, la inequidad e injusticia social caracterizan nuestra época y nuestro mundo. Las recientes cumbres internacionales del medio ambiente en Río, sobre población mundial en El Cairo y sobre desarrollo social en Copenhague reflejan intentos de hallar soluciones compartidas. Son tan vertiginosos y rápidos los cambios en todas las esferas y modalidades de la actividad humana que, hoy en día, eï ser humano se enfrenta a retos de extrema indefinición, imprevisibilidad y complejidad.

Cultivar el ejercicio del pensamiento reflexivo y crítico que conlleve al planteamiento de preguntas y cuestionamientos frente a los grandes temas de la humanidad, el soportar situaciones de inseguridad e incertidumbre manejando lo extraño y desconocido, ayudaría en la promoción de una nueva tolerancia pedagógica.

Retomo el hilo conductor que lancé al principio: nuestra postura ética frente a la práctica pedagógica. Es decir, el sentido y significación de nuestra práctica. Desde Latinoamérica y el Tercer Mundo el legado freiriano se torna punto de referencia obligado. En su Pedagogía de la Autonomía nos propone que educar exige: rigor metódico, crítica, riesgo, rechazo de cualquier discriminación, reflexión sobre la práctica, asunción de nuestra identidad cultural, autonomía, curiosidad, seguridad, generosidad, humildad, buen juicio, compromiso, alegría y libertad. Y nos reafirma: 
Estoy absolutamente convencido de la naturaleza ética de la práctica educativa, en cuanto práctica específicamente humana. No podemos asumirnos como sujetos de la búsqueda, de la decisión, de la ruptura, de la opción, como sujetos históricos, transformadores, a no ser que nos asumamos como sujetos éticos. En este sentido, la transgresión de los principios éticos es una posibilidad, pero no una virtud. No podemos aceptarla.

El fortalecimiento del sujeto se sitúa como el objetivo prioritario de la práctica educativa y se cimenta en el enriquecimiento del individuo como sujeto de sus experiencias, pensamientos, deseos y afectos. Haciéndonos eco de las palabras de Magris, nos atrevemos a afirmar que "... la utopía da sentido a la vida, porque exige, contra toda verosimilitud, que la vida tenga sentido".

\section{Referencias}

Bartoli, H. (1996). "Mundialización y desorden". En Cuadernos de Marcha, No. 113.

Beck, U. (1998). ¿Qué es la globalización?. Barcelona: Paidós.

Flecha, R. y Tortajada, I. (1999). "Retos y salidas educativas en la entrada de siglo". En La educación del siglo XXI. Barcelona: Morata

Follari, R. (1990). "Perfil del docente y crisis cultural contemporánea". En Novedades educativas, No. 59.

Freire, P. (1998). La pedagogia de la autonomía. Barcelona: Siglo XXI.

García Canclini, N. (1999). La globalización imaginada. México D.F.: Paidós.

Gimeno Sacristán, J. (1997). Poderes inestables en educación. Barcelona: Morata.

Ianni, O. (1997). Teorias de la globalización. México D.F.: Siglo XXI.

Lipovetsky, G. (1986). La era del vacio. Barcelona: Anagrama. 
Magris, C. (2000). "Utopía y desencanto". En Archipiélago, No. 40, pp. $120-127$.

Peralta, V. (2001). Globalización y construcción curricular: tensiones y posibilidades. Una perspectiva desde Latinoamérica. (Mimeografiado).

Riché, P. (Mayo, 2000). "Le monde diplomatique". En Brecha digital, suplemento especial.

Sánchez Ruiz E. Globalización y convergencia: retos para las industrias culturales latinoamericanas. Universidad de Guadalajara: Mimeografiado.

Scarlato, F. C. et al (1994). Onovo mapa do mundo. Globalizacao e espaco Latino - Americano. Ucitec/ANPUR: Sao Paulo. 